Pacific Journal of Mathematics

HEYTING ALGEBRAS WITH DUAL
PSEUDOCOMPLEMENTATION 


\title{
HEYTING ALGEBRAS WITH DUAL PSEUDOCOMPLEMENTATION
}

\author{
H. P. SANKAPPANAVAR \\ Dedicated to the memory of my daughter Saraswati
}

This paper is a contribution toward developing a theory of (the variety $H_{+}$of) Heyting algebras with dual pseudocomplementation.

1. Introduction. Initially, we set out to give a simple proof that the variety $H_{+}$has CEP - a problem kindly posed to the author by Professor H. Rasiowa in 1980 while she was visiting with him at the Instituto de Matematica, Universidade Federal da Bahia, Brasil. Our proof of CEP eventually led us to the basic result of this paper (Theorem 3.3).

The theory of $H_{+}$subsumes a significant part of the theory of double Heyting algebras and regular double $p$-algebras developed (separately) by Beazer, Katriňâk, Köhler, and others, thus providing a unifying framework. Furthermore, the study of subvarieties of $H_{+}$leads us to an infinite supply of discriminator varieties, and it turns out that all finite simple members in $H_{+}$are quasiprimal algebras. (Other results on the lattice of subvarieties of $H_{+}$will be published elsewhere.)

More specifically, we show in $\$ 3$ that the congruences on $H_{+}$-algebras are determined by normal filters, and for double Heyting algebras the $\mathrm{H}_{+}$-congruences coincide with the double Heyting algebra-congruences. In $\$ 4$ the simples, subdirectly irreducibles and directly indecomposables are characterized. Section 5 deals with characterizations of $H_{+}$-algebras with Boolean congruence lattices and Stone congruence lattices. Some of the results of $\S \S 3$ and 4 were presented to the 87 th Annual Meeting of the American Mathematical Society in January 1981 and announced in [16].

2. Preliminaries. An algebra $\mathbf{L}=\langle L, \vee, \wedge, \rightarrow,+, 0,1\rangle$ is a Heyting algebra with dual pseudocomplment if $\langle L, \vee, \wedge, \rightarrow, 0,1\rangle$ is a Heyting algebra and + is the dual pseudocomplement $\left(b \geq a^{+}\right.$iff $b \vee a$ $=1)$. $H_{+}$denotes the class of all Heyting algebras with dual pseudocomplement, and we refer to members of $H_{+}$as $H_{+}$-algebras. The class $H_{+}$is an equational class defined by the following identities (see [2]):

(1) The identities defining lattices with 0 and 1

(2) $x \wedge(x \rightarrow y) \approx x \wedge y$

(3) $x \wedge(y \rightarrow z) \approx x \wedge[(x \wedge y) \rightarrow(x \wedge z)]$ 
(4) $z \wedge[(x \wedge y) \rightarrow x] \approx z$

(5) $x \vee(x \vee y)^{+} \approx x \vee y^{+}$

(6) $x \vee 1^{+} \approx x$

(7) $1^{++} \approx 1$.

If $\mathbf{L} \in H_{+}$then $a \rightarrow 0$ is the pseudocomplement of $a \in L$, denoted by $a^{*}$, and thus $\mathbf{L}$ gives rise to a distributive double $p$-algebra $\langle L, \vee, \wedge, *,+, 0,1\rangle$. Hence, following [11], we define $a^{n(+*)}, n \in \omega$, in $\mathbf{L}$ recursively as follows: $a^{o(+*)}=a$, and $a^{(n+1)(+*)}=b^{+*}$, where $b=$ $a^{n(+*)} . \mathbf{L}$ is of finite range if, for $a \in L$, there exists $n \in \omega$ such that $a^{n(+*)}=a^{(n+1)+*}$; and $B(L)=\left\{x \in L: x=x^{* *}\right\}$, while $\bar{B}(L)$ is defined dually. The center of $L$, Cen $L$, is the Boolean sublattice of complemented elements of $\mathbf{L}$. We introduce the notion of normal filter in $\mathbf{L}$ which plays a crucial role for the theory of $H_{+}$-algebras. A lattice filter $F$ [ideal I] of $\mathbf{L}$ is normal iff $a^{+*} \in F\left[a^{*+} \in I\right]$ whenever $a \in F[a \in I]$. We denote the (algebraic) lattice of normal filters in $L$ by $\mathrm{NF}(L)$ and the set of its compact elements by $\operatorname{Comp}(\operatorname{NF}(L))$. For $a, b \in L$ we write $a \uparrow b$ if $a^{n\left(+^{*}\right)} \leq b$ for some $n \in \omega$.

An algebra $\mathbf{A}=\langle A, \vee, \wedge, \rightarrow, \leftarrow, 0,1\rangle$ is a double Heyting algebra if $\langle A, \vee, \wedge, \rightarrow, 0,1\rangle$ is a Heyting algebra and $\langle A, \vee, \wedge, \leftarrow, 0,1\rangle$ is a dual Heyting algebra. If $\mathbf{A}$ is a double Heyting algebra, then $\langle A, \vee$, $\wedge, \rightarrow,+, 0,1\rangle$ is an $H_{+}$-algebra with $a^{+}=a \leftarrow 1$. A double $p$-algebra is regular if $a^{*}=b^{*}$ and $a^{+}=b^{+}$imply $a=b$ for its elements $a, b$. A regular double $p$-algebra can be regarded (see [11]) as a double Heyting algebra, where $a \rightarrow b$ is defined as

$$
a \rightarrow b=\left(a^{*} \vee b^{* *}\right)^{* *} \wedge\left[\left(a \vee a^{*}\right)^{+} \vee a^{*} \vee b \vee b^{*}\right],
$$

and $a \leftarrow b$ is defined dually - this remark will be used frequently without mention in the sequel.

Unless otherwise stated, $L$ denotes an arbitrary $H_{+}$-algebra throughout. If $A \subseteq L$ and $A \neq \varnothing$, then $N(A)$ denotes the normal filter of $L$ generated by $A$ (where $N(a)$ denotes $N(\{a\})$, and $A^{l}$ denotes the set of lower bounds of $A$ in $L$, while $D(L)=\left\{x \in L: x^{*}=0\right\}$ ).

LEMMA 2.1. If $A \subseteq L$ and $A \neq \varnothing$, then

$$
N(A)=\left\{x \in L: x \geq\left(a_{1} \wedge \cdots \wedge a_{n}\right)^{m(+*)}\right.
$$

for some $a_{i} \in A$ and $\left.m \in \omega\right\}$;

and if $a \in L$ then $N(a)=\bigvee_{m \in \omega}\left[a^{m(+*)}\right)$.

Corollary 2.2. If $J$ is a filter of Cen $L$ then

$$
N(J)=\{x \in L ; x \geq \text { a for some } a \in J\} .
$$


Lemma 2.3. Let $a \in$ Cen $L$. Then

(1) $\left(\right.$ a] $\in H_{+}$,

(2) The function $x \mapsto x \wedge a$ is an $H_{+}$-homomorphism of L onto (a].

Proof. It is well known (see [2]) that (a] is a Heyting algebra. For $x \in(a]$ we let $x^{+a}=x^{+} \wedge a$. Then it is easy to see that $x^{+a}$ is the dual pseudocomplement of $x$ in $(a]$, since $a \in \operatorname{Cen} L$.

Corollary 2.4 If $a \in \operatorname{Cen} L$, then $L \cong(a] \times\left(a^{\prime}\right]$.

3. Congruence lattices as normal filter lattices. In this section we prove our basic results namely that the congruences on an $\mathrm{H}_{+}$-algebra are determined by normal filters, and $H_{+}$-congruences (preserving $\wedge, \vee, \rightarrow$, + ) coincide with the congruences (preserving $\wedge, \vee, \rightarrow, \leftarrow$ ) on a double Heyting algebra, and we give several applications of these results, which include some recent results of Katriňák, Köhler and Beazer on double Heyting algebras and regular double $p$-algebras.

Lemma 3.1. Let $\theta \in \operatorname{Con} L$. Then $1 / \theta$ is a normal filter in $\mathbf{L}$.

Proof. Observe $1^{+*}=1$.

LEMMA 3.2. Let $F \in \mathrm{NF}(L)$ and define a relation $\theta(F)$ by $x \equiv y \theta(F)$ iff $x \wedge f=y \wedge f$ for some $f \in F$. Then $\theta(F)$ is a congruence on $L$ such that $1 / \theta(F)=F$.

Proof. It is well known that $\theta(F)$ is a Heyting algebra-congruence (e.g., see [1]) such that $1 / \theta(F)=F$. Now let $\langle a, b\rangle \in \theta(F)$; then $a \wedge f=$ $b \wedge f$ for some $f \in F$ and so $a^{+} \vee f^{+}=b^{+} \vee f^{+}$using the identity $(x \wedge y)^{+}$ $\approx x^{+} \vee y^{+}$. Hence, $\left(a^{+} \vee f^{+}\right) \wedge f^{+*}=\left(b^{+} \vee f^{+}\right) \wedge f^{+*}$, from which it follows that $a^{+} \wedge f^{+*}=b^{+} \wedge f^{+*}$. Since $F$ is normal, $f^{+*} \in F$ so that $\left\langle a^{+}, b^{+}\right\rangle \in F$, proving the lemma.

The following theorem is basic to what follows and will be frequently used without explicit reference to it.

THEOREM 3.3. Con $L \cong \mathrm{NF}(L)$.

Proof. We claim that the function $\theta: \operatorname{NF}(L) \rightarrow \operatorname{Con} L, F \mapsto \theta(F)$, is an isomorphism. If $\alpha \in$ Con $L$ then, in view of Lemma 3.2 it suffices to prove $\alpha=\theta(1 / \alpha)$. If $\langle a, b\rangle \in \alpha$, using $y \rightarrow y \approx 1$ we have

$$
\langle(a \rightarrow b) \wedge(b \rightarrow a), 1\rangle \in \alpha
$$


so that

$$
f=(a \rightarrow b) \wedge(b \rightarrow a) \in 1 / \alpha .
$$

Use the identity $x \wedge(x \rightarrow y) \approx x \wedge y$ to conclude that $a \wedge f=b \wedge f$.

COROllary 3.4. The variety $H_{+}$has CEP.

Definition 3.5. Let $H_{+n}$ denote the subvariety of $H_{+}$defined by the identity $(n \in \omega)$

$$
x^{n(+*)} \approx x^{(n+1)(+*)} .
$$

Note that $H_{+0}$ is the (sub)variety of Boolean algebras.

COROLlary 3.6. For each $n \in \omega$ the variety $H_{+n}$ has equationally definable principal congruences.

The following (surprising) result will enable us to show that a significant part of the theories of double Heyting algebras and regular double p-algebras can be subsumed in the theory of $H_{+}$-algebras.

THeOREM 3.7. Let $A$ be a double Heyting algebra. Then every $H_{+}-$congruence on $A$ is a congruence on $A$.

Proof. Let $\theta$ be an $H_{+}$-congruence on $A$ and $\langle x, y\rangle \in \theta$ and $\langle u, w\rangle$ $\in \theta$. Then $x \wedge f=y \wedge f$ and $u \wedge g=w \wedge g$ for some $f, g \in 1 / \theta$; hence, $x \vee f^{+}=y \vee f^{+}$and $u \vee g^{+}=w \vee g^{+}$. Now

$$
\begin{aligned}
(x \leftarrow u) \vee f^{+} \vee g^{+} & =f^{+} \vee g^{+} \vee\left[\left(f^{+} \vee g^{+} \vee x\right) \leftarrow\left(f^{+} \vee g^{+} \vee u\right)\right] \\
& \quad \text { by the dual of (3) } \\
& =f^{+} \vee g^{+} \vee\left[\left(f^{+} \vee g^{+} \vee y\right) \leftarrow\left(f^{+} \vee g^{+} \vee w\right)\right] \\
& =f^{+} \vee g^{+} \vee(y \leftarrow w) .
\end{aligned}
$$

It is now immediate that $\langle x \leftarrow u, y \leftarrow w\rangle \in \theta$, since $\left\langle f^{+} \vee g^{+}, 0\right\rangle \in \theta$.

Corollary 3.8. (Köhler [13].) If $A$ is a double Heyting algebra then Con $A \cong \mathrm{NF}(L)$.

We remarked in $\S 2$ that a regular double $p$-algebra is a double Heyting algebra, so we have the following corollary.

Corollary 3.9. (Katriňák [1], Beazer [3].) If $A$ is a regular double p-algebra then $\operatorname{Con} A \cong \mathrm{NF}(A)$. 
Thus, on a regular double $p$-algebra double $p$-algebracongruences, $H_{+}$-congruences and double Heyting algebracongruences all coincide.

We conclude this section by noting that there are easy examples of $H_{+}$algebras (e.g., 4-element chain) such that not every lattice-congruence compatible with + and $*$ is an $\boldsymbol{H}_{+}$-congruence.

4. Simples, (finitely) subdirectly irreducibles and indecomposables. In this section we characterize directly indecomposables (see [7] for definition), finitely subdirectly irreducibles, subdirectly irreducibles and simples in $H_{+}$, influenced by the works of Beazer, Katriňák and Köhler.

THEOREM 4.1. Let $|L|>1$. Then TFAE:

(1) $L$ is directly indecomposable

(2) Cen $L=\{0,1\}$.

Proof. We may assume $|L|>2$. If $a \in \operatorname{Cen} L-\{0,1\}$ then $L$ $\cong(a] \times\left(a^{\prime}\right]$, showing that $(1) \Rightarrow(2)$. For $(2) \Rightarrow(1)$ let $\theta, \bar{\theta}$ be a pair of factor congruences different from $\Delta$ and $\nabla$ (see [7]). Then $\theta \wedge \bar{\theta}=\Delta$ and $\theta \circ \bar{\theta}=\nabla$. Let $F_{1}=1 / \theta$ and $F_{2}=1 / \bar{\theta}$; then $F_{1} \wedge F_{2}=\{1\}$ and there exists $a \in L-\{0,1\}$ such that $0 \theta a \bar{\theta} 1$. Hence, $a \in F_{2}$ and $a^{*} \in F_{1}$ so that $a \vee a^{*} \in F_{1} \wedge F_{2}=\{1\}$; thus $a \in \mathrm{Cen} L$, which shows that (2) $\Rightarrow$ (1).

Using Theorem 3.7 we now have

COROLlary 4.2. The equivalence of (1) and (2) in Theorem 4.1 holds for double Heyting algebras and regular double p-algebras.

THEOREM 4.3. Let $|L|>2$. Then TFAE:

(1) L is simple

(2) Cen $L=\{0,1\}$, and for every $x \in D(L)-\{1\}$ there exists $n \in \omega$ such that $x^{n(+*)}=0$.

Proof. Suppose $L$ is simple. Then it follows from Theorem 4.1 that Cen $L=\{0,1\}$. Let $x \in D(L)-\{1\}$, and since $L$ is simple, $N(x)=L$ so that $0 \in N(x)$. Thus there exists $n \in \omega$ such that $x^{n(+*)}=0$. Conversely, if $a \in L-\{1\}$ then it suffices to show that $N(a)=L$. Now $x=a \vee a^{*}$ $\in D(L)$. Since $\operatorname{Cen}(L)=\{0,1\}$ we see that $x \neq 1$. Then from the hypothesis we conclude that $0 \in N(x) \leq N(a)$, so that $N(a)=L$.

Theorems 4.3 and 3.7 together yield the following. 
COROllary 4.4. (Köhler [13], Beazer [5].) The equivalence of (1) and (2) is also true of double Heyting algebras and of regular double p-algebras.

COROLLARY 4.5. Let $L$ be of finite range and $|L|>1$. Then TFAE:

(1) $L$ is simple

(2) L is subdirectly irreducible

(3) L is finitely subdirectly irreducible

(4) $L$ is directly indecomposable

(5) Cen $L=\{0,1\}$.

Proof. The implications $(1) \Rightarrow(2) \Rightarrow(3) \Rightarrow(4)$ are well known and (4) $\Rightarrow$ (5) follows from Theorem 4.1, while (5) $\Rightarrow$ (1) by Theorem 4.3.

The above corollary is an extension, and an improvement, of corresponding results for double Heyting algebras and regular double $p$-algebras due to Beazer, Katriňák and Köhler. The corollary also implies that every simple algebra is hereditarily simple.

LeMma 4.6. Let $a \in L$. Then the pseudocomplement of $N(a)$ in $\operatorname{NF}(L)$ is given by

$$
N(a)^{*}=\left\{x \in L: x^{+} \leq a^{n(+*)} \text { for every } n \in \omega\right\} .
$$

TheOrem 4.7. Let $|L|>1$. Then TFAE:

(1) $L$ is finitely subdirectly irrecducible (see [7] for definition)

(2) $\Lambda_{n \in \omega} a^{n(+*)}=0$ for every $a \in L-\{1\}$

(3) $\Lambda_{n \in \omega} a^{n(+*)}=0$ for every $a \in \bar{B}(L)-\{1\}$

(4) $N(a)$ is dense in $\mathrm{NF}(L)$ for every $a \in L-\{1\}$.

Proof. (1) $\Leftrightarrow$ (4) is clear from Theorem 3.3 and the fact that $\mathrm{NF}(L)$ is a pseudocomplemented lattice.

(4) $\Rightarrow(2)$. Let $a \in L-\{1\}$ and let $m \leq a^{n(+*)}$ for every $n \in \omega$. Then $m^{*+} \leq a^{n(+*)}$ for every $n \in \omega$ by using the implication $x \leq y^{+*} \Rightarrow x^{*+} \leq$ $y$; hence, by Lemma 4.6, $m^{*} \in N(a)^{*}=\{1\}$; thus $m=0$, implying (2).

(2) $\Rightarrow(4)$. Suppose there is an $a \in L-\{1\}$ such that $N(a)$ is not dense. Then there exists $m \in L-\{1\}$ such that $m \in N(a)^{*}$ so that $0<m^{+} \leq a^{n(+*)}$ for every $n \in \omega$, hence, $\bigwedge_{n \in \omega} a^{n(+*)} \geq m^{+}>0$.

Finally, for (3) $\Rightarrow(2)$ it suffices to note that if $a \in L-\{1\}$, then $a^{n(+*)}=a^{++n(+*)}$ and $a^{++} \in \bar{B}(L)-\{1\}$.

In view of 3.7 we obtain

COROLlaRy 4.8. (Beazer [6].) The equivalences in the above theorem also hold for double Heyting algebras (and for regular double p-algebras). 
Beazer's proof of the above corollary, however, made essential use of the existence of the dual Heyting implication $\leftarrow$.

LEMMA 4.9. If $\bigwedge_{n \in \omega} a^{n(+*)}=0$ for all $a \in \bar{B}(L)-\{1\}$, then Cen $L=$ $\{0,1\}$.

Proof. The hypothesis implies by 4.7 that $\wedge_{n \in \omega} a^{n(+*)}=0$ for all $a \in L-\{1\}$, and the rest of the proof is the same as that of Theorem 2 in [1].

THEOREM 4.10. Let $|L|>2$. Then TFAE

(1) $L$ is subdirectly irreducible but not simple.

(2) (i) $\Lambda_{n \in \omega} a^{n(+*)}=0$ for all $a \in \bar{B}(L)-\{1\}$, and

(ii) there exists $d \in D(L)-\{1\}$ such that $x \uparrow d \uparrow 0$ for all $x \in$ $D(L)-\{1\}$.

(3) (i) Cen $L=\{0,1\}$ and

(ii) (2)(ii) holds.

Proof. (1) $\Rightarrow$ (2). Now (2)(i) follows from (1) by Theorem 4.7, and (1) implies that there exists a principal normal filter $N(a)$ such that $\{1\} \subset$ $N(a) \subset L$ and $N(a)$ is contained in every normal filter $N(x)$ of $L$ for $x \neq 1$, implying that $x^{n(+*)} \leq a$. Now let $d=a \vee a^{*} \in D(L)$, and $d \neq 1$ since, otherwise, $a \in \operatorname{Cen} L=\{0,1\}$, whence $a=0$ which is a contradiction. If $d \uparrow 0$ then for some $n \in \omega, d^{n(+*)}=0$, so that $0 \in N(a)$, which is impossible since $N(a) \neq L$. Finally, if $x \in D(L)-\{1\}$, then $N(a) \subseteq$ $N(x)$, so $x^{n(+*)} \leq a \leq d$, proving (1) $\Rightarrow$ (2). Next, (2) $\Rightarrow$ (3) follows immediately from Lemma 4.9 .

(3) $\Rightarrow(1)$. Observe that $N(d) \neq\{1\}$ and $N(d) \neq L$, since $d\{0$. Let $F \in \mathrm{NF}(L)$ be such that $\{1\} \subset F \subset L$, and let $x=f \vee f^{*}$ for some $f \in F \backslash\{1\}$. Then, $x \in F$ and $x \in D(L)$. Since Cen $L=\{0,1\}$, we have $x \neq 1$. Thus, by hypothesis, $x^{n(+*)} \leq d$ for some $n \in \omega$, implying that $d \in F$, so $N(d) \subseteq F$. This shows that $L$ is subdirectly irreducible but not simple.

Theorems 4.10 and 3.7 yield the following

Corollary 4.11. (Katriñák [12], Beazer [5].) The equivalence of (1), (2), and (3) holds for double Heyting algebras and regular double p-algebras.

It is shown in [1] that the converse of Lemma 4.9 is not true. We conclude this section by pointing out another proof of this fact: Suppose 
the converse of Lemma 4.9 holds. In view of Theorems 4.1 and 4.7 it follows that every directly indecomposable algebra in $H_{+}$is finitely subdirectly irreducible. Then by the proof of Theorem 12.5 in [7], $H_{+}$is semisimple, which is impossible, since there are known to exist non-simple subdirectly irreducible doubly Heyting algebras, and such algebras are non-simple subdirectly irreducibles in $H_{+}$, as well in view of 3.7.

5. $\mathbf{H}_{+}$-algebras with Boolean congruence lattices. There are many results in the literature characterizing algebras with Boolean congruence lattices in a given variety. For example, pseudocomplemented semilattices with Boolean congruence lattices are characterized in [15]. (See references in [15] for more such results.)

In this section we characterize those members of $H_{+}$whose join-semilattice of compact congruences is actually a Boolean lattice as well as those $L \in H_{+}$for which Con $L$ is a Boolean lattice.

LEMMA 5.1. If $a, b \in L$ then $N(a) \vee N(b)=N(a \wedge b)$.

LEMMA 5.2. $F \in \mathrm{NF}(L)$ is compact iff $F=N(a)$ for some $a \in L$.

THEOREM 5.3. TFAE:

(1) Comp $(\mathrm{NF}(L))$ is a Boolean sublattice of $\mathrm{NF}(L)$

(2) $\operatorname{Comp}(\mathrm{NF}(L))$ is complemented

(3) $L$ is of finite range

(4) $\mathrm{NF}(L) \cong F($ Cen $L)$.

Proof. It suffices to prove the implications $(2) \Rightarrow(3) \Rightarrow(1)$, since (3) $\Rightarrow(4)$ holds for any distributive double $p$-algebra (see [3]).

$(2) \Rightarrow(3)$ : Let $a \in L$; then by (2) $N(a)$ has a complement in $\operatorname{NF}(L)$. Thus there is an $F \in \mathrm{NF}(L)$ such that $N(a) \wedge F=\{1\}$ and $N(a) \vee F=$ $L$. Hence, by Grätzer [10], Lemma 5, p. $60, F$ is principal, say $F=$ $N(b)$ for $b \in L$. Since $0 \in N(a) \vee N(b)$, there exists $n \in \omega$ such that $(a \wedge b)^{n(+*)}=0$, that is, $a^{n(+*)} \wedge b^{n(+*)}=0$. Also $a^{n(+*)} \vee b^{n(+*)} \in$ $N(a) \wedge N(b)=\{1\}$, so $b^{n(+*)}$ is a complement of $a^{n(+*)}$, and hence $a^{n(+*)} \in \operatorname{Cen} L, a^{n(+*)}=a^{(n+1)(+*)}-$ thus proving that $L$ is of finite range.

$(3) \Rightarrow(1)$. In view of 5.2 it suffices to show that the principal normal filters form a Boolean sublattice of $\operatorname{NF}(L)$. Let $a, b \in L$; then $a^{n(+*)}=$ $a^{(n+1)(+*)}=x$ (say) and $b^{m(+*)}=b^{(m+1)(+*)}=y$ (say). Now $N(a)=[x)$ and $N(b)=[y)$, so $N(a) \wedge N(b)=[x \vee y)$, and $[x \vee y)$ is normal since $x \vee y \in \operatorname{Cen} L$; thus $\operatorname{Comp}(\operatorname{NF}(L))$ is a sublattice of $\operatorname{NF}(L)$. Finally, since $N(a)=[x)$ and $x \in$ Cen $L$, it follows that the complement of $N(a)$ is the principal normal filter $\left[x^{\prime}\right)$. 
COROLlaRY 5.4. If $L \in H_{+n}$ then the compact congruences on $L$ form a Boolean sublattice of $\mathrm{NF}(L)$.

This corollary and a result of S. Burris together imply that the variety $H_{+n}$ is a discriminator variety for $n \in \omega$. However, one can also write a dicriminator term for $H_{+n}$. For example, if we let $d(x)=x^{n(+*)}$, then the following term is the ternary discriminator on each of the simple algebras in $H_{+n}$ :

$$
\begin{aligned}
t(x, y, z)= & {[z \wedge d((x \vee y) \rightarrow(x \wedge y))] } \\
& \vee[x \wedge(d((x \vee y) \rightarrow(x \wedge y))) *] .
\end{aligned}
$$

Corollary 5.5. (Epstein and Horn [9].) If $A$ is a P-algebra, then $\mathrm{NF}(L) \cong F(\operatorname{Cen} L)$, and also the compact congruences form a Boolean sublattice. Hence P-algebras form a discriminator variety.

THEOREM 5.6. TFAE:

(1) Con $L$ is a Boolean lattice

(2) $L$ is of finite range and $\mathrm{Cen} L$ is finite

(3) Con $L$ is a finite Boolean lattice.

Proof. (1) $\Rightarrow(2)$. Let $x \in L$, then $N(x)$ has a complement $F \in \mathrm{NF}(L)$ by (1). Since $0 \in N(x) \vee F$, there exists an $f \in F$ and $n \in \omega$ such that

$$
0=(x \wedge f)^{n(+*)}=x^{n(+*)} \wedge f^{n(+*)} .
$$

From $x^{n(+*)} \in N(x)$ and $f^{n(+*)} \in F$ it follows that $x^{n(+*)} \vee f^{n(+*)} \in$ $N(x) \wedge F=\{1\}$; thus $x^{n(+*)} \in$ Cen $L$, and hence $L$ is of finite range. Then it follows from 5.3 that $\operatorname{Cen} L$ is finite. For $(2) \Rightarrow(3)$, we again use 5.3 to get $\mathrm{NF}(L) \cong F(\operatorname{Cen} L)$, and since Cen $L$ is finite, it follows that $\mathrm{NF}(L)$, and hence Con $L$, is a finite Boolean lattice.

COROLlary 5.7. Theorem 5.6 also holds for double Heyting algebras.

Theorem 5.6 generalizes a result of Beazer [3].

The following theorem and its corollary were presented by the author to the 57th Ontario Mathematical Meeting held at London, Ontario, Canada, on February 7, 1981. The referee of this paper pointed out to the author that these results also follows from (Theorem 3.3 and) a recent result proved by $\mathrm{R}$. Beazer, Lattices whose ideal lattice is Stone, Proc. Edinburgh Math. Soc. (1983), 107-212. We therefore state these results without proofs. 
THEOREM 5.8. Let $L$ be an $H_{+}$-algebra or a double Heyting algebra. Then TFAE:

(1) $\mathrm{NF}(L)$ is a Stone lattice

(2) $\wedge F$ exists in $L$ for all $F \in \operatorname{NF}(L)$

(3) $\wedge S$ exists in $L$ for all $S \subseteq$ Cen $L$ and $\wedge_{n \in \omega} a^{n(+*)}$ exists in $L$ for all $a \in L$

(4) Con $L$ is a Stone lattice.

COROLlaRY 5.9. Let $\mathrm{L}$ be an $\mathrm{H}_{+}$-algebra or a double Heyting algebra of finite range. Then $\operatorname{Con} L$ is a Stone lattice iff $\operatorname{Cen} L$ is a complete (Boolean) lattice.

Acknowledgments. The author is extremely grateful to Professors Stanley Burris and Denis Higgs and to the Pure Mathematics Department of the University of Waterloo for making his visits to Waterloo possible, and for their hospitality. $\mathrm{He}$ is also indebted to the referee for his valuable comments.

\section{REFERENCES}

[1] M. E. Adams and T. Katriňák, A note on subdirectly irreducible distributive double p-algebras, J. Austrailian Math. Soc., (Ser. A) 35 (1983), 46-58.

[2] A. Balbes and P. Dwinger, Distributive lattices, Univ. of Missouri Press, Columbia, 1974.

[3] R. Beazer, The determination congruence on double p-algebras, Algebra Universalis, 6 (1976), 121-129.

[4] Regualr double p-algebras with Stone congruence lattices, Algebra Universalis, 9 (1979), 238-243.

[5] Subdirectly irreducible double Heyting algebras, Algebra Universalis, 10 (1980), 220-224.

[6] _ Finitely subdirectly irreducible algebras with pseudocomplementation, Algebra Universalis, 12 (1981), 376.

[7] S. Burris and H. P. Sankappanavar, A Course in Universal Algebra, Springer-Verlag, New York, 1981.

[8] B. Davey, Subdirectly irreducible distributive double p-algebras, Algebra Universalis, 8 (1978), 73-88.

[9] G. Epstein and A. Horn, P-algebras, an abstraction from Post algebras, Algebra Universalis, 4 (1974), 195-206.

[10] G. Grätzer, General Lattice Theory, Birkhauser-Verlag, Basel, 1976.

[11] T. Katriňák, The structure of distributive double p-algebras, Regularity and congruences, Algebra Universalis, 3 (1973), 238-246.

[12] ___ Subdirectly irreducible distributive double p-algebras, Algebra Universalis, 10 (1980), 195-219.

[13] P. Köhler, A subdirectly irreducible double Heyting algebra which is not simple, Algebra Universalis, 10 (1980), 189-194. 
[14] H. Rasiowa, Algebraic Approach to Non-classical logics, North-Holland, 1974.

[15] H. P. Sankappanavar, Pseudocomplemented semilattices with Stone congruence lattices, Math. Slovaca, 29 (1979), 381-395.

[16] H. P. Sankappanavar, Heyting algebras with dual pseudocomplementation, Abstracts of papers presented to the American Mathematical Society. Vol. 2, Issue 1 (1981), Abs 783-06-19.

[17] H. Werner, Discriminator Algebras, Studien zur Algebra und ihre Anwendungen, Band 6, Akademie-Verlag, Berlin, 1978.

Received June 17, 1983 and in revised form October 28, 1983.

Current address: State University of New York

New Paltz, NY 12561 



\section{PACIFIC JOURNAL OF MATHEMATICS EDITORS}

DONALD BABBITT (Managing Editor)
University of California
Los Angeles, CA 90024
CHARLES R. DEPrIMA
California Institute of Technology
Pasadena, CA 91125
R. FINN
Stanford University
Stanford, CA 94305

\author{
HERMANN FLASCHKa \\ University of Arizona \\ Tucson, AZ 85721 \\ RAMESH A. GANGOLLI \\ University of Washington \\ Seattle, WA 98195 \\ ROBION KIRBY \\ University of California \\ Berkeley, CA 94720 \\ C. C. Moore \\ University of California \\ Berkeley, CA 94720
}

Hugo Rossi

University of Utah

Salt Lake City, UT 84112

H. SAMELSON
Stanford University
Stanford, CA 94305

HAROLD STARK

University of California, San Diego

La Jolla, CA 92093

\section{ASSOCIATE EDITORS}
R. ARens
E. F. BECKENBACH (1906-1982)
B. H. NeUmanN
F. WOLF
K. YOSHIDA

\begin{tabular}{ll}
\multicolumn{2}{c}{ SUPPORTING INSTITUTIONS } \\
UNIVERSITY OF ARIZONA & UNIVERSITY OF OREGON \\
UNIVERSITY OF BRITISH COLUMBIA & UNIVERSITY OF SOUTHERN CALIFORNIA \\
CALIFORNIA INSTITUTE OF TECHNOLOGY & STANFORD UNIVERSITY \\
UNIVERSITY OF CALIFORNIA & UNIVERSITY OF HAWAII \\
MONTANA STATE UNIVERSITY & UNIVERSITY OF TOKYO \\
UNIVERSITY OF NEVADA, RENO & UNIVERSITY OF UTAH \\
NEW MEXICO STATE UNIVERSITY & WASHINGTON STATE UNIVERSITY \\
OREGON STATE UNIVERSITY & UNIVERSITY OF WASHINGTON
\end{tabular}

The Supporting Institutions listed above contribute to the cost of publication of this Journal, but they are not owners or publishers and have no responsibility for its content or policies.

\footnotetext{
Mathematical papers intended for publication in the Pacıfic Journal of Mathematıcs should be in typed form or offset-reproduced (not dittoed), double spaced with large margins. Please do not use built up fractions in the text of the manuscript. However, you may use them in the displayed equations. Underline Greek letters in red, German in green, and script in blue. The first paragraph must be capable of being used separately as a synopsis of the entire paper. In particular it should contain no bibliographic references. Please propose a heading for the odd numbered pages of less than 35 characters. Manuscripts, in triplicate, may be sent to any one of the editors. Please classify according to the scheme of Math. Rev ews, Index to Vol. 39. Supply name and address of author to whom proofs should be sent. All other communications should be addressed to the managing editor, or Elaine Barth, University of California, Los Angeles, California 90024.

There are page-charges associated with articles appearing in the Pacific Journal of Mathematics. These charges are expected to be paid by the author's University, Government Agency or Company. If the author or authors do not have access to such Institutional support these charges are waived. Single authors will receive 50 free reprints; joint authors will receive a total of 100 free reprints. Additional copies may be obtained at cost in multiples of 50 .
}

The Pacific Journal of Mathematics is issued monthly as of January 1966. Regular subscription rate: $\$ 190.00$ a year (5 Vols., 10 issues). Special rate: $\$ 66.00$ a year to individual members of supporting institutions.

Subscriptions, orders for numbers issued in the last three calendar years, and changes of address should be sent to Pacific Journal of Mathematics, P.O. Box 969, Carmel Valley, CA 93924, U.S.A. Old back numbers obtainable from Kraus Periodicals Co., Route 100, Millwood, NY 10546.

The Pacific Journal of Mathematics at P.O. Box 969, Carmel Valley, CA 93924 (ISSN 0030-8730) publishes 5 volumes per year. Application to mail at Second-class postage rates is pending at Carmel Valley, California, and additional mailing offices. Postmaster: Send address changes to Pacific Journal of Mathematics, P.O. Box 969, Carmel Valley, CA 93924.

PUBLISHED BY PACIFIC JOURNAL OF MATHEMATICS, A NON-PROFIT CORPORATION Copyright $\odot 1985$ by Pacific Journal of Mathematics 


\section{Pacific Journal of Mathematics}

\section{Vol. 117, No. 2 \\ February, 1985}

Robert Walter Bagley, Ta-Sun Wu and J. S. Yang, On a class of topological groups more general than SIN groups ............... 209

Bruce Alan Barnes, Algebraic elements of a Banach algebra modulo an ideal ...............................................219

Howard D. Fegan and Peter Gilkey, Invariants of the heat equation .......233

Erica Flapan, Necessary and sufficient conditions for certain homology

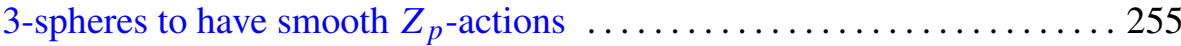

Philip R. Heath, Product formulae for Nielsen numbers of fibre maps . . . . 267

Derbiau Frank Hsu and A. Donald Keedwell, Generalized complete mappings, neofields, sequenceable groups and block designs. II ...... 291

Taqdir Husain, Orthogonal primitive idempotents and Banach algebras

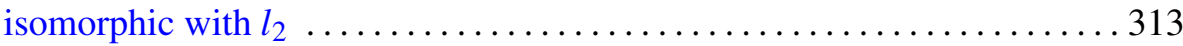

Gary M. Lieberman, Regularized distance and its applications . . . . . . . 329

William W. Menasco, Determining incompressibility of surfaces in alternating knot and link complements ............................ 353

Benjamin Muckenhoupt, Weighted reverse weak type inequalities for the Hardy-Littlewood maximal function $\ldots \ldots \ldots \ldots \ldots \ldots \ldots \ldots \ldots \ldots \ldots \ldots$

John Dacey O'Neill, Direct summands of direct products of slender

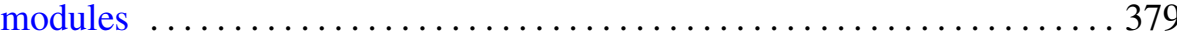

Andreas Rapp, Elimination of Malitz quantifiers in stable theories 387

Francisco José Ruiz, A unified approach to Carleson measures and $A_{p}$ weights

Hanamatagouda Pandappa Sankappanavar, Heyting algebras with dual

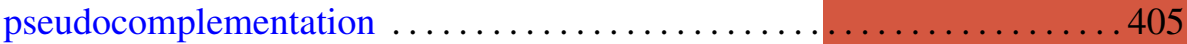

Annette Sinclair, Strong Carleman and strong uniform approximation . . . . 417

Masaaki Suzuki, The generalized Schwarz lemma for the Bergman metric

Brian Thorpe and Ludwig Tomm, Universal approximation by regular

weighted means 